\title{
BCCiN4
}

\section{DEVELOPING REINFORCED FOAM CONCRETE AS A COMPOSITE MATERIAL FOR DURABLE STRUCTURAL APPLICATION}

\author{
Gideon P.A.G. van Zijl and Algurnon S. van Rooyen \\ Department of Civil Engineering, Stellenbosch University, South Africa
}

https://doi.org/10.21452/bccm4.2018.02.22

\begin{abstract}
A research programme in Stellenbosch University was launched to develop and characterize lightweight foam concrete for structural application. A particular aim is to develop the material with sound mechanical and durability properties for structural application in load bearing walling systems of low to medium rise residential infrastructure. The benefits of thermal and sound insulation make it an ideal construction material for residences in hot or fluctuating climates. In particular, its low self-weight may be exploited in regions of seismic activity, leading to lower inertia forces in earthquake ground acceleration. Having been in use for nearly a century, its use has been dominantly for non-structural insulation and backfill for drainage. In the past decade it has received renewed attention as potential structural material. Significantly improved mechanical properties are reported in this contribution. Also, the closed pore structure, despite the high percentage of pores, is visualized. Results of carbonation-induced and chloride-induced corrosion of embedded steel in LWFC are presented. To illustrate the potential of a structural walling system, results of recent pull-over laboratory tests and modelling are presented on a R/LWFC walling system comprising a founding beam, two interconnected wall panels, and an upper beam simulating upper floor restraint. The modular construction method, foam concrete, and on-site connection systems are shown to present behavior viable for application in industry.
\end{abstract}

Keywords Foam concrete; steel reinforcement; carbonation; chloride-ingress; corrosion

\section{INTRODUCTION}

Lightweight foam concrete (LWFC) originates from early in the previous century. Applications are dominated by non-structural applications such as insulation and backfill for drainage [1, 2]. The base composition of this composite material comprises a cement paste prepared by mixing cement and water, and subsequent addition of pre-mixed foam to form the air voids. Aggregates can be added, and cement can be partially replaced by alternative binder or filler materials such as fly ash. It is characterized by a porous microstructure which is responsible for its superior thermal performance compared to normal weight concrete. At the same time, the voids are responsible for its relatively low compressive strength, stiffness and 
fracture energy [3]. In order to exploit the light weight and insulation properties in structural application, advances have been made in developing and characterizing the mechanical properties and durability. While foam concrete can be produced in a wide density range, a density range of 1200 to $1600 \mathrm{~kg} / \mathrm{m}^{3}$ is believed to hold potential for structural use [2, 3]. Optimization of the paste, which forms the skeleton of LWFC, and improved foaming agents to form well-dispersed, small diameter air voids have led to significant advances in mechanical behavior. Micro-fiber reinforcement may be an additional ingredient to either control early age shrinkage and potential plastic shrinkage cracking, or to reinforce the composite in the hardened state. To advance structural applications of foamed concrete, the durability behavior of reinforced LWFC over time, as well as how to adequately reinforce a material with lower fracture energy must be understood. The following sections present an overview of recent results of mechanical and durability characterization.

\section{DEVELOPMENT OF MECHANICAL PROPERTIES}

Recent development has led to improved mechanical performance of LWFC [1-5]. Table 1 summarizes a subset of LWFC mixes developed and characterized by the authors at Stellenbosch University.

Mix design improvements have led to the ability to accurately design for desired densities in the range 1000 to $1600 \mathrm{~kg} / \mathrm{m}^{3}$. In this range, the air voids comprise a significant portion of the composite, up to $40-50 \%$ by volume. As expected, increased air content leads to reduced strength and stiffness in the hardened state. However, the skeleton composition, and control of the air voids to remain fine and well-dispersed, enable strengths to be achieved that suffice for structural application. Figure 1 shows LWFC compressive and tensile strength as function of density. Note that the strength values are normalized to that of a standard class $40 \mathrm{MPa}$ concrete for the purpose of illustration. Error bars for $1400 \mathrm{~kg} / \mathrm{m}^{3}$ show the possible range in strength obtained by the authors for various paste compositions. Stiffness, here in terms of Young's Modulus E, is shown to be approximately proportionate to density, despite the disproportionate compressive and tensile strengths. Fracture energy has been found to be low, but improved by [5] as reflected by the $G_{f}$ error bar for $1400 \mathrm{~kg} / \mathrm{m}^{3} \mathrm{LWFC}$ by inclusion of $0.35 \%$ by volume of polypropylene fiber of length $12 \mathrm{~mm}$ and diameter $0.04 \mathrm{~mm}$.

Bond of LWFC with ribbed steel reinforcement bars is also shown to be relatively low in Figure 1. Note that these bond values were determined by beam-end tests [3] for LWFC without fiber. This motivated the work to increase fracture energy [5], whereby it is believed the splitting cracking caused in steel bar bond failure is controlled, whereby the bond is significantly improved. Beam-end tests have not yet been repeated for fiber LWFC, but in Section 4 the tests on steel reinforced LWFC wall system did not exhibit debonding of steel, but rather expected crack patterns in the R/LWFC walls indicating proper composite action.

Table 1: Mix compositions 


\begin{tabular}{|c|c|c|c|c|c|c|c|c|c|c|c|c|}
\hline & & & & & & & & \multicolumn{3}{|c|}{ et al. [7] } & & \\
\hline & \multicolumn{3}{|c|}{$A: C=0$} & $A: C=1$ & \multicolumn{3}{|c|}{$A: C=2$} & \multicolumn{3}{|c|}{$A: C=1$} & LWFC & NWC \\
\hline Target Casting Density $\left[\mathrm{kg} / \mathrm{m}^{3}\right]$ & \multicolumn{7}{|c|}{1600} & \multicolumn{3}{|c|}{1400} & 1550 & 2400 \\
\hline Dry density & \multicolumn{7}{|c|}{1450} & \multicolumn{3}{|c|}{1250} & 1400 & \\
\hline Wet density & \multicolumn{7}{|c|}{$1600 \pm 25$} & \multicolumn{3}{|c|}{$1375 \pm 15$} & $1550 \pm 25$ & \\
\hline CEM II-52.5 [kg] & \multicolumn{3}{|c|}{1110} & 593.3 & \multicolumn{3}{|c|}{404.4} & \multicolumn{3}{|c|}{511.7} & 371.8 & 378 \\
\hline Fly-ash, Class S [kg] & \multicolumn{3}{|c|}{0} & 593.3 & \multicolumn{3}{|c|}{808.9} & \multicolumn{3}{|c|}{511.7} & 743.7 & 122.5 \\
\hline Coarse aggregate $6-9 \mathrm{~mm}[\mathrm{~kg}]$ & \multicolumn{3}{|c|}{0} & 0 & \multicolumn{3}{|c|}{0} & \multicolumn{3}{|c|}{0} & 0 & 769.5 \\
\hline Polypropylene Fiber [kg] & \multicolumn{3}{|c|}{5} & 5 & \multicolumn{3}{|c|}{5} & \multicolumn{3}{|c|}{0} & 4.1 & 0 \\
\hline Malmesbury Sand [kg] & \multicolumn{3}{|c|}{0} & 0 & \multicolumn{3}{|c|}{0} & \multicolumn{3}{|c|}{0} & 0 & 972 \\
\hline Water [Litre] & \multicolumn{3}{|c|}{475} & 403.3 & \multicolumn{3}{|c|}{375.6} & \multicolumn{3}{|c|}{358.2} & 479.7 & 180 \\
\hline Foam [kg] & \multicolumn{3}{|c|}{12.8} & 10.4 & \multicolumn{3}{|c|}{9.5} & \multicolumn{3}{|c|}{18.4} & 4.819 & $\mathrm{~N} / \mathrm{A}$ \\
\hline Super Plasticizer [kg] & \multicolumn{3}{|c|}{0} & 0 & \multicolumn{3}{|c|}{0} & \multicolumn{3}{|c|}{0} & 0 & 7.56 \\
\hline Compressive strength: $\quad$ age(d) & 1 & 28 & 56 & & 1 & 28 & 56 & $28 \mathrm{~d}$ & $56 \mathrm{~d}$ & $112 d$ & & \\
\hline $\begin{array}{ll} & \text { Reference (untreated) } \\
(\mathrm{MPa}) & \text { Integral }^{1} \\
& \text { Surface }^{\text {treated }}{ }^{2} \\
\end{array}$ & 18.5 & 30.5 & 34.5 & & 3.5 & 18.5 & 25.5 & \begin{tabular}{|c|}
22 \\
28.5 \\
18.5 \\
\end{tabular} & $\begin{array}{c}25 \\
33.7 \\
22.5 \\
\end{array}$ & $\begin{array}{l}20.3 \\
32.3 \\
21.2 \\
\end{array}$ & & \\
\hline
\end{tabular}

${ }^{1}$ Integral water repellant agent Sikalite or Chryso Fuge B

${ }^{2}$ Surface treatment painted on, Sikagard 706 Thixo, 0.2\% wt binder) 200-300 g/m²

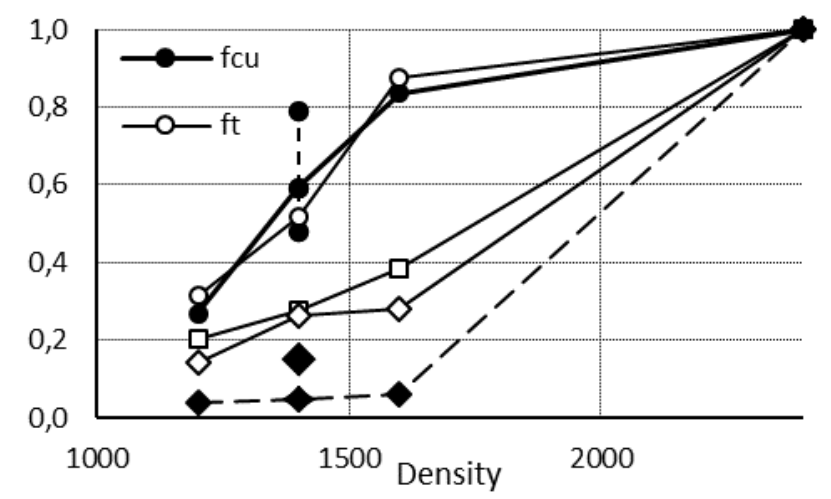

Figure 1: Normalized strength $\left(f_{c u}, f_{t}\right)$, stiffness $(E)$, fracture energy $\left(G_{f}\right)$ and bond stress of LWFC, showing recent improvements for $1400 \mathrm{~kg} / \mathrm{m}^{3}$ in $f_{c u}$ and $G_{f}$ with error bars.

\section{DURABILITY OF LWFC}

Optimized LWFC has a porous, yet cellular, closed microstructure. Figure 1(a) shows the pore size distribution, and their interconnectivity is shown in Figure 2(b) through X-Ray computer tomography (CT) of a $1400 \mathrm{~kg} / \mathrm{m}^{3}$ LWFC included in Table 1, with A:C=1. For the particular LWFC the mean pore size was found to be $310 \mu \mathrm{m}$, and this was slightly reduced to $286 \mu \mathrm{m}$ in the case of integral water repellence treatment of the same LWFC mix. Importantly, the pores are interconnected to only an insignificant degree, which is important for ingress of deleterious substances into LWFC.

Durability tests have been performed on LWFC, and a summary is given in Table 2 . Reference, untreated LWFC, as well as specimens treated for water repellence through mixing the water repellence agent into the matrix, denoted integral in Table 2, and others that were surface coated after curing were included in the experimental programs. Carbonation and chloride-induced corrosion were investigated. Cover depths of $20 \mathrm{~mm}$ and $35 \mathrm{~mm}$ to single 12 $\mathrm{mm}$ diameter steel reinforcement bars were used in chloride aqueous solution cyclic ponding tests for accelerated corrosion of R/LWFC. In the case of carbonation, only a $35 \mathrm{~mm}$ cover depth was used. See Figure 3 for full details of the durability tests, the reader is referred to [6] and [7]. 
Figures 3(a) and (b) show results of chloride profiling and carbonation depth from these tests. It must be noted that drying shrinkage restraint by the embedded reinforcement bars caused crack formation in the specimens, which are illustrated in Figure 4 on plan views of the $500 \mathrm{~mm} \times 100 \mathrm{~mm} \times 100 \mathrm{~mm}$ specimens used for chloride-induced corrosion, for all mix types (A:C $=0,1,2)$ and cover depths $(20 \mathrm{~mm}, 35 \mathrm{~mm})$. Chloride profiles were obtained by drilling into the specimens after 9 week of cyclic ponding with chloride aqueous solution [4], collecting the powder and performing X-Ray Fluorescence (XRF) to determine the total chloride content. This was done by drilling into cracks, and into uncracked parts respectively, denoted by cracked and uncrakced in the legend of Figure 3(a). It is clear that for surface treated LWFC, whether cracked or uncracked, the chloride penetration was limited. For integral water repellent LWFC, chloride did not penetrate deep into uncracked LWFC, but in the crack, significant amount of chloride penetrated to the surface of the reinforcing bar. This amount was only exceeded by the cracked, untreated LWFC. To prevent restrained shrinkage cracks, Grafe (2017) developed a fiber reinforced LWFC, which is included in the second last column of Tables 1 and 2, as used by [5] for large scale wall system testing. The fibers prevented restrained shrinkage cracks in those mixes, despite inclusion of reinforcing steel meshes, as reported in Section 3.

The carbonation depth did not reach the level of steel (Figure 3(b)), and no corrosion initiated in those specimens. Corrosion did initiate and propagate in the accelerated chlorideinduced specimens, ascribed to the restrained shrinkage cracks. Figure 4 summarizes corrosion rates in the various R/LWFC specimens.

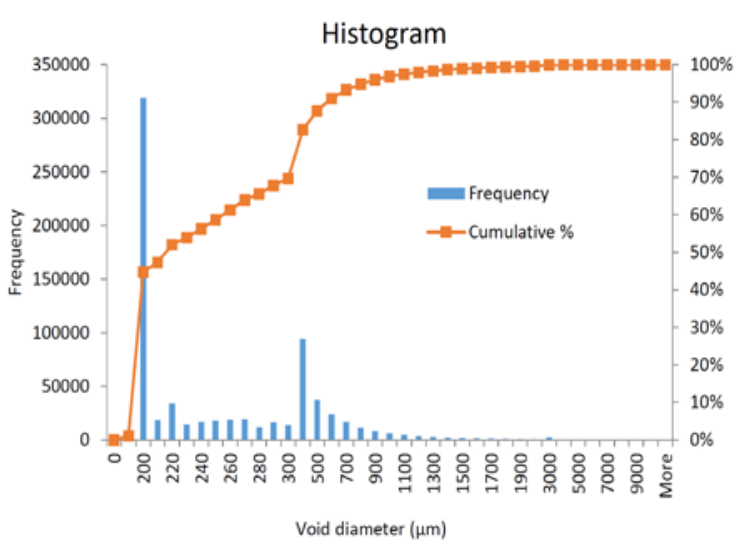

(a)

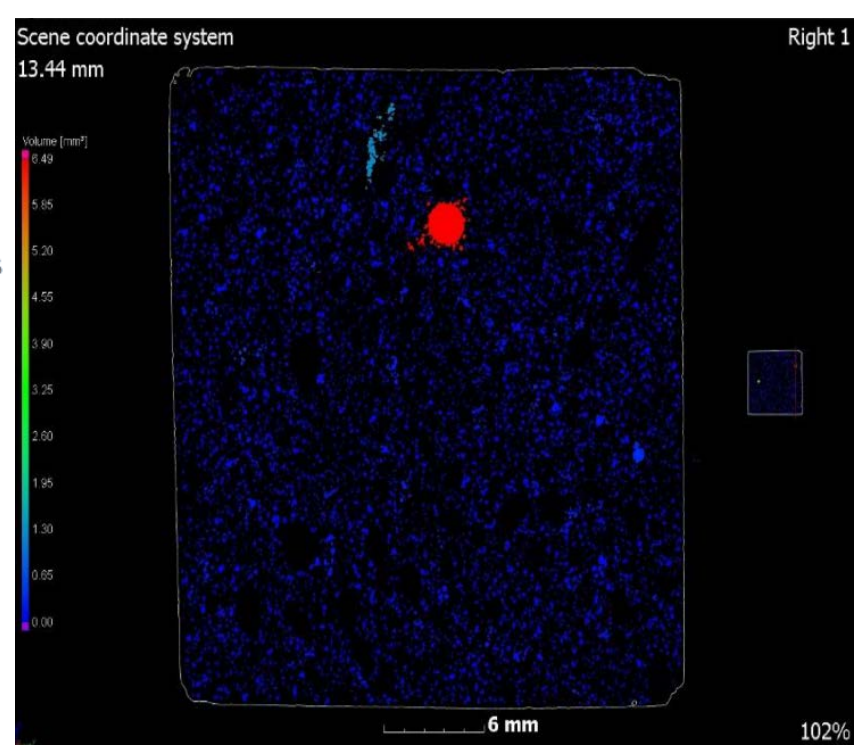

(b)

Figure 2: LWFC of density $1400 \mathrm{~kg} / \mathrm{m}^{3}$ air void (a) diameter distribution and (b) connectivity.

Table 2: Durability properties of LWFC

\begin{tabular}{|c|c|c|c|c|}
\hline & \multicolumn{3}{|c|}{ Zvinokona et al. [6] } & Mabatapasango et al. [7] \\
\hline & A:C=0 & A:C=1 & A:C=2 & A:C=1 \\
\hline Target Casting Density $\left[\mathrm{kg} / \mathrm{m}^{3}\right]$ & \multicolumn{3}{|c|}{1600} & 1400 \\
\hline $\begin{array}{c}\text { Water penetration depth (mm) } \\
\text { Reference (untreated) }\end{array}$ & & & & \\
Integral & & & $4.5^{3}$ \\
Surface treated & & & & \\
\hline
\end{tabular}




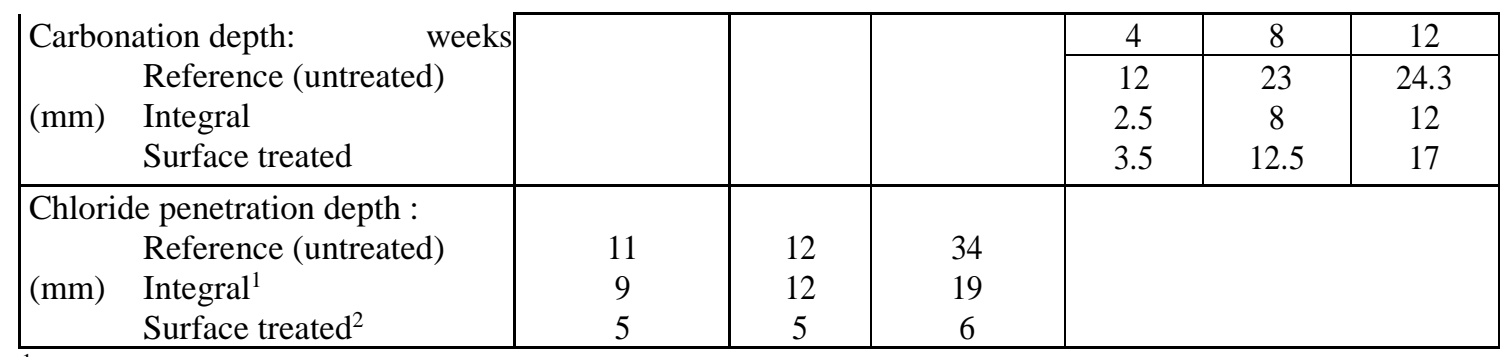

${ }^{1}$ Integral water repellant agent Sikalite or Chryso Fuge B

${ }^{2}$ Surface treatment painted on, Sikagard 706 Thixo, 0.2\% wt binder) $200-300$ g/m²

${ }^{3}$ Water penetration depth test according to EN 1504-2:2004

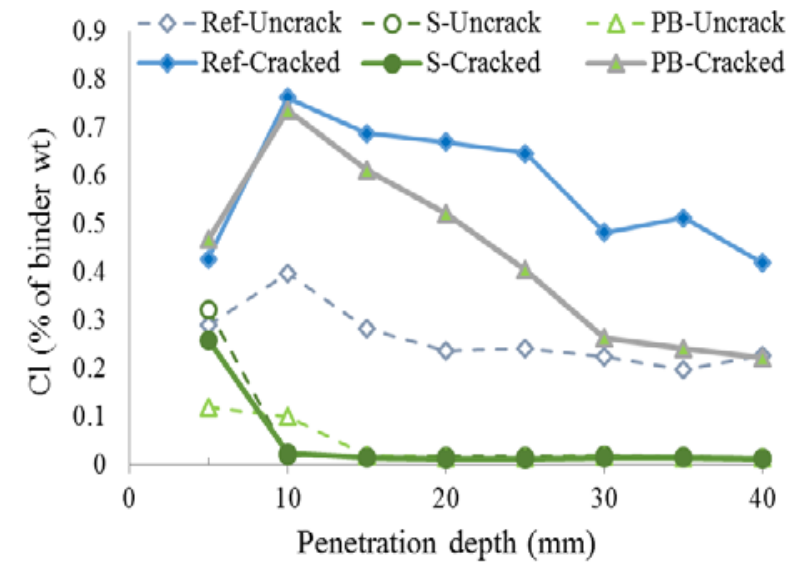

(a)

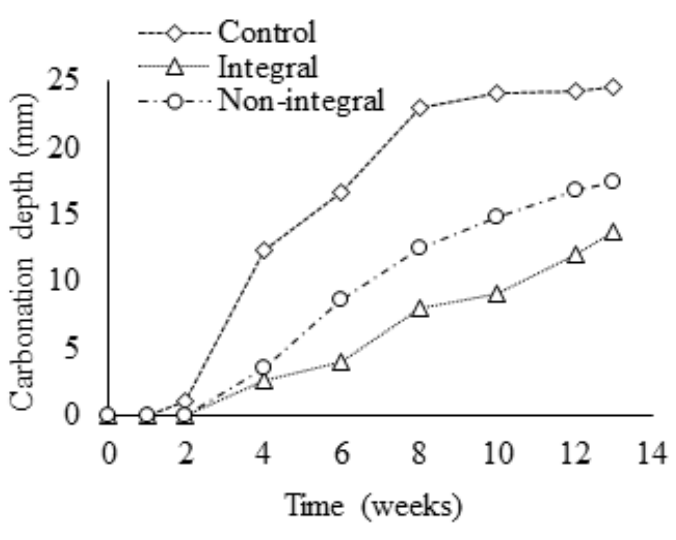

(b)

Figure 3: (a) Chloride profiles in LWFC specimens after 9 weeks of cyclic ponding with Chloride aqueous solution, (b) carbonation depth [4]. 

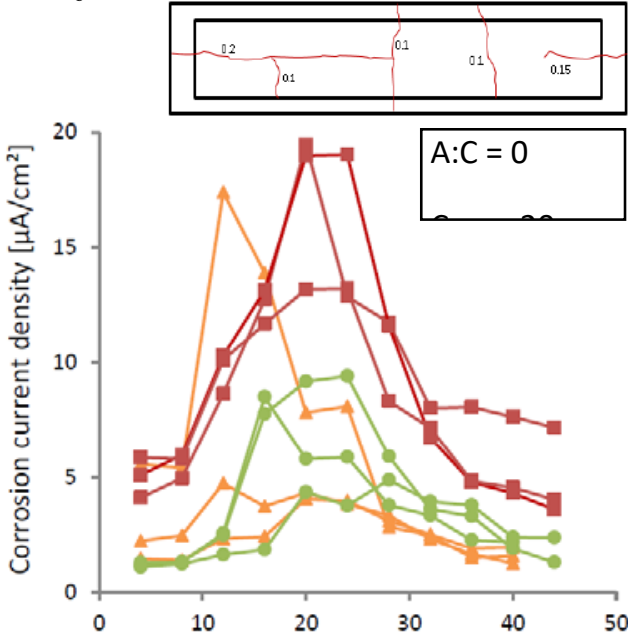

(a)

Reinforcement length $[\mathrm{cm}]$

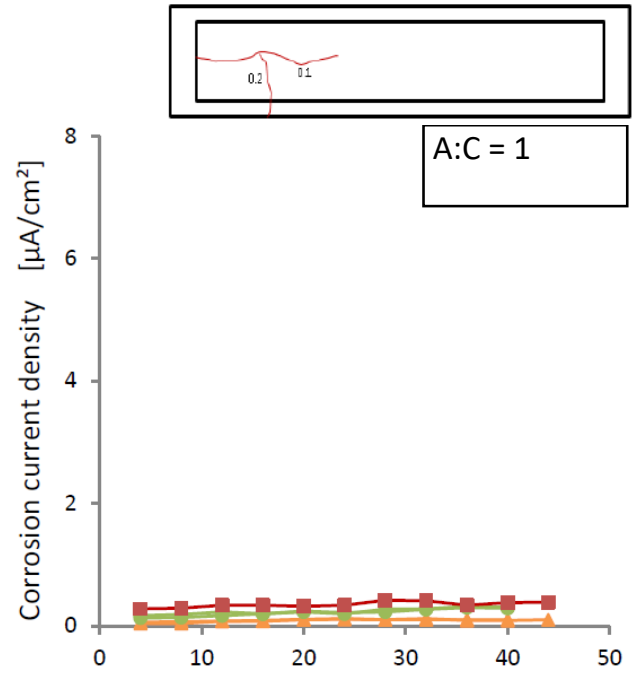

(c)

Reinforcement length [cm]

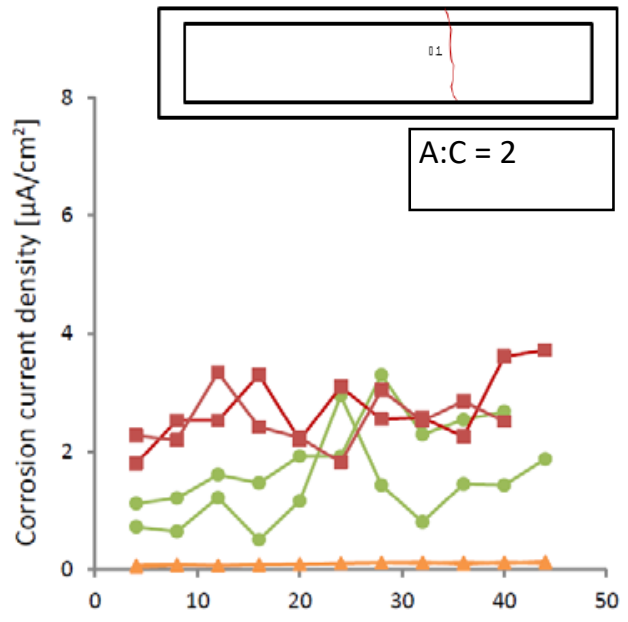

(e)

Reinforcement length $[\mathrm{cm}]$
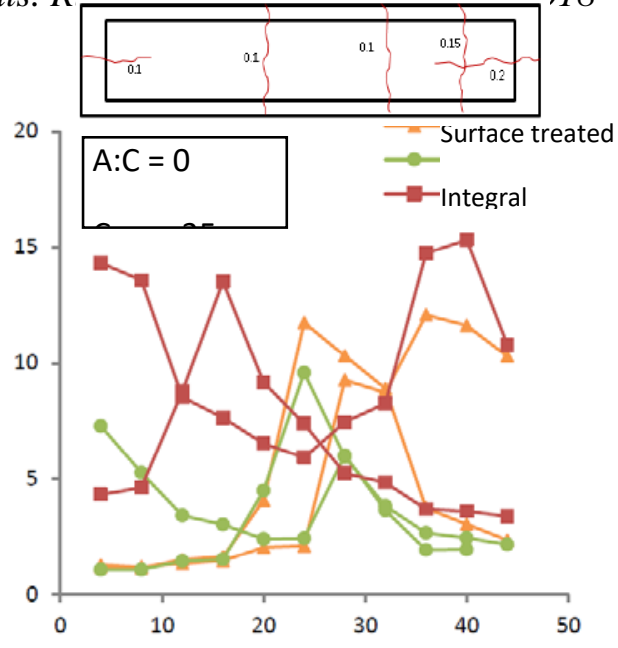

(b)

Reinforcement length [cm]

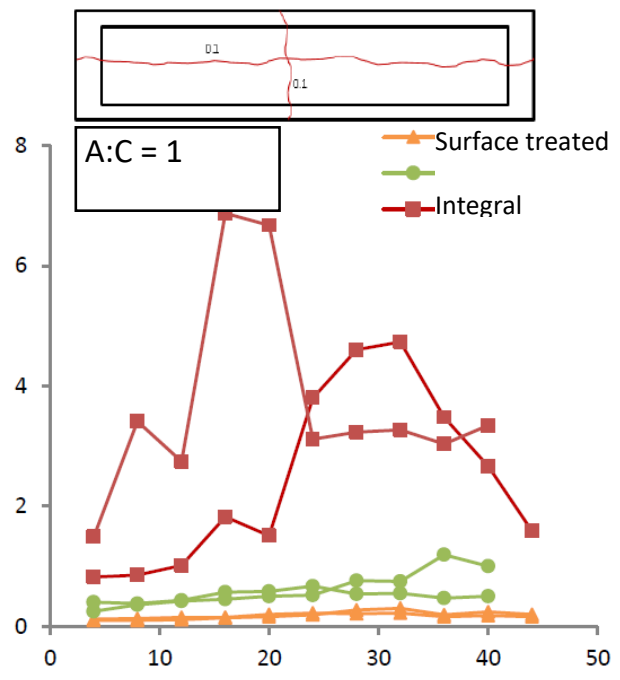

(d)

Reinforcement length [cm]

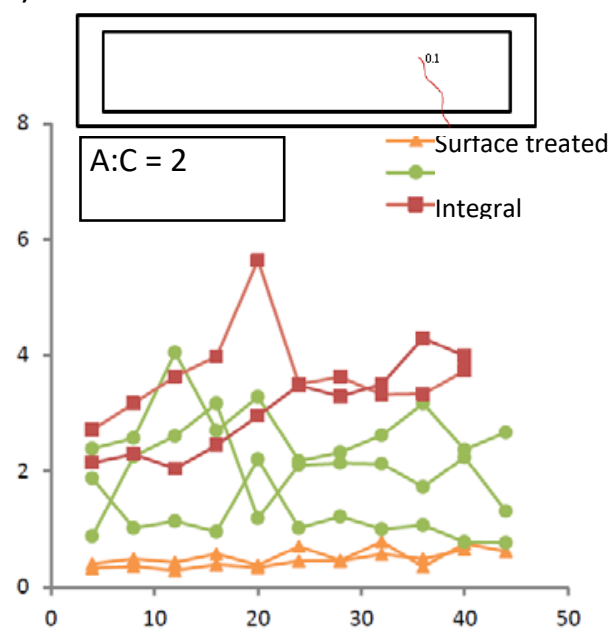

(f)

Reinforcement length [cm]

Figure 4: Corrosion rate in R/LWFC specimens with various Fly Ash to Cement ratios $(0,1,2)$, and cover to steel $(20 \mathrm{~mm}, 35 \mathrm{~mm})$. Typical crack patterns and widths are also shown.

\section{STRUCTURAL R/LWFC WALLING SYSTEM}

A R/LWFC walling system is proposed that consists of connected precast reinforced LWFC panels. Current residential infrastructure in the Western Cape of South Africa comprise mainly 
of unreinforced, load bearing masonry (URM) and precast, hollow-core floors. These three and four storey buildings do not conform to the SANS 10160-4:2017 seismic design criteria and are susceptible to the low-moderate peak ground acceleration of $a_{g}=0.15 \cdot g$ predicted for the area. As an alternative structural system, a LWFC walling system will take advantage of the thermal, acoustic and fire-resistant properties of LWFC, as well as light weight and associated low inertia forces. This structural system will also contribute to reduce the housing backlog through high quality, high output factory production, and sustained employment in industrialized construction.

To test the proposed walling system, a wall section of a prototype building shown in Figure 5(a) is modelled for laboratory testing as well as finite element analysis. The scaled test assembly (Figure 5b) comprise two wall panels, each of dimensions $1380 \times 920 \times 150(\mathrm{~mm})$, and two reinforced concrete panels/beams to simulate a foundation and floor interaction. The concrete mix design for both the LWFC and NWC panels are given in Table 1. Each wall panel was reinforced with two layers of a local South African (Ref .193) steel mesh, comprising of $5.6 \mathrm{~mm}$ diameter, $520 \mathrm{MPa}$ yield strength steel bar at a grid spacing of $200 \mathrm{~mm}$ x $200 \mathrm{~mm}$, placed with $40 \mathrm{~mm}$ cover from each wall face. The walls were precast horizontally in wooden moulds, and after 14 days tilted up and transported from the Materials Laboratory to the Structures Laboratory for assembly. Heat curing can be employed and removal of the moulds can be done within days. The vertical dashed lines in Figure 5(b) indicate the locations of grouted dowels along the horizontal connections, each consisting of a $12 \mathrm{~mm}$ diameter, 520 MPa yield stress steel bar, encased in a $40 \mathrm{~mm}$ diameter PVC pipe and grouted with SikaGrout ${ }^{\circledR} 212$. Wall 1 had three dowels per panel per interface. The four horizontal connections (boxed in red) are the connections that were removed as a variable for the second pull-over test, in Wall 2. The vertical connection boxes between the two wall panels are shown in Figure 5(d). These horizontal connections follow the precast connection guidelines outlined in the New Zealand building codes [8,9]. This guideline suggests that reinforcement across a connection be less than the reinforcement within the wall, to ensure failure at the connections where ductility can be confirmed.

The self-weight load of the structure above was applied to the wall system via springs to the top of the wall and distributed through a $254 x 254 x 89$ structural steel H-section. The walls were displaced through a $500 \mathrm{kN}$ Instron Mechanical Testing Machine (MTM) and transferred across the structural steel section by embedded shear bolts into the top NWC panel. Details of the experimental setup can be found in Dunn et al. (2017).

The results indicated sound responses of the two wall systems to quasi-static pull-over. Figure 6 shows the responses of Wall 1 and Wall 2, with distinct difference caused by the connection system. Recall that fewer dowel connectors were included in Wall 2 than Wall 1 (Figure 5b). This led to a separate rotation of the two wall parts (Figure 6a), due to balanced vertical and horizontal connection detail, and subsequent larger pull-over resistance and energy dissipation in Wall 1 than Wall 2 (Figure 6(a) versus Figure 6(b)). Moreover, well-developed patterns of, diagonal fine cracks were observed in Wall 1, but less in Wall 2, explaining the lower ductility of Wall 2 than that of Wall 1.

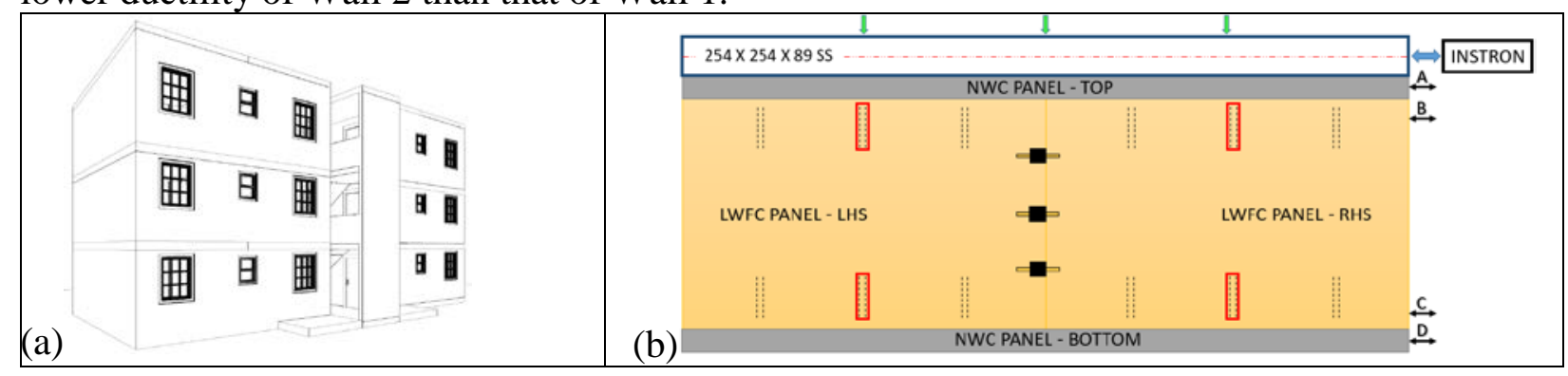




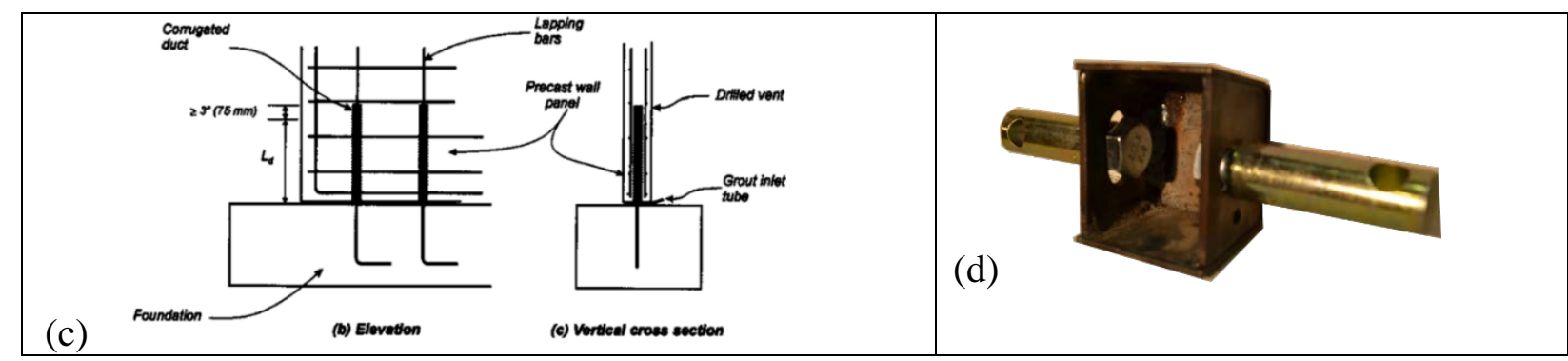

Figure 5: (a) Prototype residential building, (b) wall test section comprising two interconnected wall panels, a foundation and floor beams, (c) illustration of foundation-wall dowel connections and (d) photo of the wall panel connectors used in vertical joints.

1.
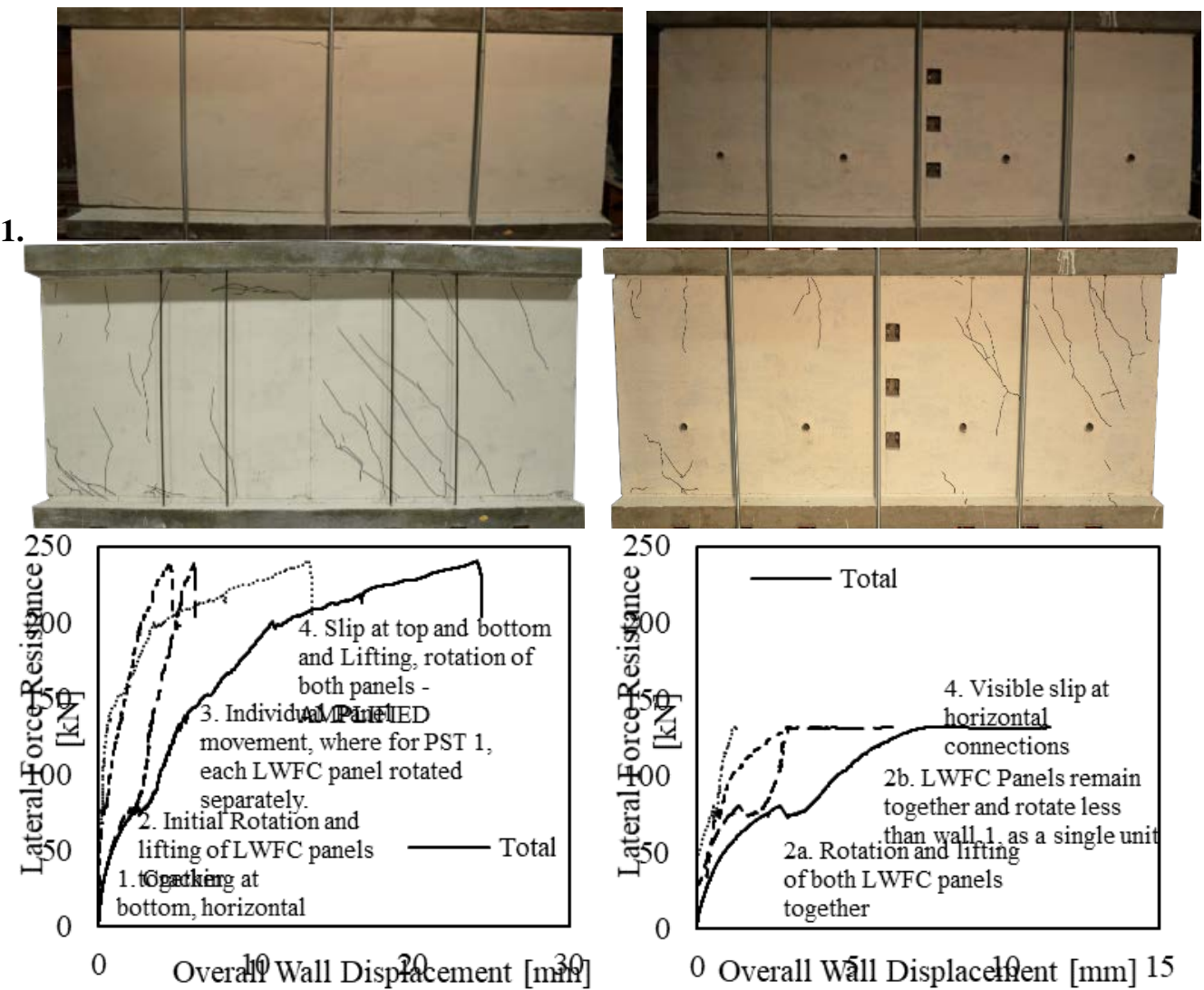

(a) Wall 1 response

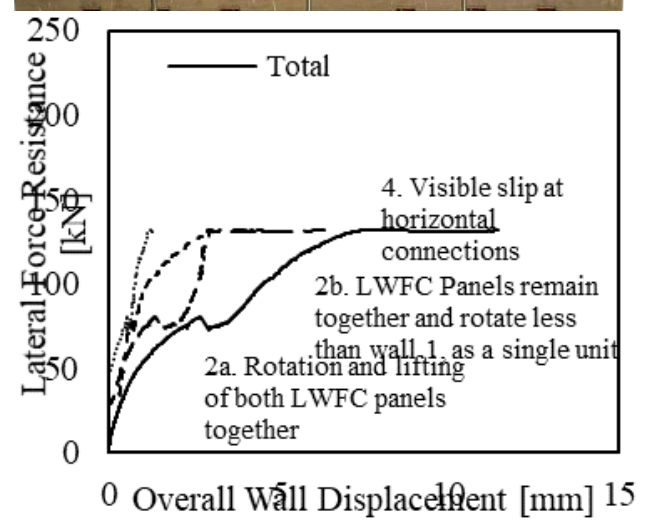

(b) Wall 2 response

Figure 6: (a) Separate wall panel rotation with 3 dowel connections per wall part and lower and upper beams, versus (b) wall panels rotating together as a single unit in two dowel connections per panel per interface.

\section{CONCLUSIONS}

Lightweight foam concrete can be used structurally, thanks to the development in materials technology to improve the strength and stiffness, as well as fracture energy. Inclusion of a small amount of micro fiber prevents the formation of restrained shrinkage cracks. In absence of cracks, carbonation and chloride penetration is restricted, even more so if integral, or preferably surface treatment is applied for water repellence. Yet, even without such treatment, the closed, fine, dispersed pore structure in foam concrete prevents significant ingress of deleterious materials. Thereby, deterioration processes like chloride-induced corrosion, are slow. 
$4^{\text {th }}$ Brazilian Conference on Composite Materials. Rio de Janeiro, July $22^{\text {nd }}-25^{\text {th }}, 2018$

\section{REFERENCES}

[1] Kearsley, E. and Mostert, H. 2005. Designing mix composition of foamed concrete with high fly ash contents. In: Use of Foamed Concrete in Construction: Proceedings of the International Conference held at the University of Dundee, Scotland, UK on 5 July 2005, pp. 29-36. Thomas Telford Publishing.

[2] Jones, M.R., McCarthy, A. 2005. Preliminary views on the potential of foamed concrete as a structural material, Magazine of Concrete Research 200557(1)21-31.

[3] De Villiers, J.P., van Zijl, G.P.A.G., van Rooyen, A.S. 'Bond of deformed steel reinforcement in lightweight foamed concrete (LWFC)'. Structural Concrete, international journal of fib, June 2017, 18(3): 496-506.

[4] Van Rooyen, A.S., Van Zijl, G.P.A.G. 'Chloride profiling of integral and non-integral surface treated Lightweight foamed concrete'. Paper ID 120, $71^{\text {st }}$ RILEM week and ICACMS, 3-8 September 2017, Chennai, India, pp. 11-16.

[5] Dunn T.P.A., Van Rooyen, A.S., Van Zijl, G.P.A.G. 'Reinforced Lightweight Foamed Concrete for Seismically Resistant Low-rise Residential Buildings', Paper ID 101, $71^{\text {st }}$ RILEM week and ICACMS, 3-8 September 2017, Chennai, India, Volume 3, pp. 269-278.

[6] Zvinokona, A.R., Van Rooyen, A.S., Bezuidenhout, S.R., Van Zijl, G.P.A.G. 'Chloride-induced corrosion in structural lightweight foam concrete'. In: $9^{\text {th }}$ International Symposium on Cement and Concrete (ISCC2017), 1-3 November 2017, Wuhan, China.

[7] Mubatapasango, M.S., Van Rooyen, A.S., Van Zijl, G.P.A.G. 'Effect of surface protection on carbonation induced corrosion in reinforced foam concrete'. Paper ID 114, $71^{\text {st }}$ RILEM week and ICACMS, Proceedings International conference on Advances in Construction Materials and Systems 2017, 3-8 September 2017, Chennai, India, pp. 179-188.

[8] Seifi, P., Henry, R. \& Ingham, J., 2016. Panel connection details in existing New Zealand precast concrete buildings. Bulletin of the New Zealand Society for Earthquake Engineering.

[9] New Zealand Concrete Society, 1999. Guidelines for the Use of Structural Precast Concrete in Buildings. Christchurch: University of Canterbury. 